were advised to contact the doctor. A proportion of these patients may have sought a consultation with a doctor, rather than telephoning as we suggested, because the delay in treatment had meant that they were experiencing more asthma than usual.

In their pilot study on hospital patients Beasley et al chose $70 \%$ as the value at which to implement changes in treatment. ${ }^{9}$ Once patients have been taught the importance of their symptoms $75 \%$ or $80 \%$ may be a more appropriate criterion in general practice. Fifty per cent as the point of introducing oral steroid treatment was selected by Beașley et al because it was observed that morning dips with a fall in peak flow of more than $50 \%$ of the highest daily peak flow preceded sudden death. ${ }^{1314}$ In general practice, where the patients with asthma may not be so severely affected, a lower cut off point of $45 \%$ or possibly $40 \%$ may be appropriate. This may reduce the use of oral steroids but increase the need for treatment with nebulised drugs and time lost from work and school. The earlier introduction of inhaled steroids may help compensate for this effect.

The study was carried out on a population of both adults and children. The analysis showed no major differences between the two. This confirms our belief that a standard self management plan whether directed by symptoms or peak flows is applicable to children and adults alike.

The peak flow meter has a well established place in the care of asthma. Peak flow meters are soon to be available on prescription in the NHS. It is a timely reminder that simply prescribing peak flow meters without a system of self management and regular review will be unlikely to improve patient care. Techniques that teach the patients the importance and relevance of their symptoms and how to implement changes in management are vitally important if asthma care is to be improved.

Our study raises some interesting questions about the use of peak flow meters in general practice. In an attempt to overcome some of these problems we have developed a colour coded peak flow meter ${ }^{15}$ which helps the patient easily learn the concepts of self management and modify treatment appropriately. Such a system together with modified cut off points may well help the meter play an important part in the long term management of asthma in general practice.

We thank the Clare Wand fund, the Scientific Foundation of the Royal College of General Practitioners, and Vitalograph for providing support funds. We thank Drs P C S Chapman, $\mathrm{J}$ L Christie, K R Harrison, and K Elsby and staff at the Aylsham surgery for their cooperation, and Professor John Bain and Dr Roger Jones of the Primary Medical Care Group at the University of Southampton for their advice throughout the study. We dedicate this paper to the late Dr David Williams, whose guidance made this project a reality.

1 Battu K, Collins-Williams C, Zaleskyey C. Evaluation of home monitoring of asthmatic children with the mini-Wright peak flow meter. $\mathcal{F}$ Asthma 1982;19:93-7.

2 Prior JG, Cochrane GM. Home monitoring of peak expiratory flow rate using mini-Wright peak flow meter in the diagnosis of asthma. $f R$ Soc Med 1980;73:731-3.

3 McGuinness BV. A Wright peak flow meter in practice. Practitioner 1982; 226:21.

4 Wright BM. Wright's peak flow meter. BMF 1978;ii:1627-8.

5 Anonymous. Self monitoring of peak expiratory flow rate in asthma. Drug Ther Bull 1982 Sep 17:73-4.

6 Williams AJ, Church SE. Availability of mini peak flow meters for the management of severe asthma. Lancet 1985; i:1341.

7 Rubinfield AR, Pain MCF. The perception of asthma. Lancet 1976;i:882-4.

8 Sibbald B. Patient self-care in acute asthma. Thorax 1989;44:97-101.

9 Beasley R, Cushley M. Holgate ST. A self management plan in the treatment of adult asthma. Thorax 1989;44:200-4.

10 Charlton IH, Charlton GFA, Broomfield J, Mullee M. Asthma care in general practice: evaluation of a nurse run asthma clinic. British fournal of General practice: evaluation

11 Norusis MJ. The SPSS guide to data analysis for SPSS/PC+. Chicago: SPSS, 1989.

12 Ryan BF, Joiner BL, Ryan TA. Minitab handbook. 2nd ed. Boston: Duxbury, 1985 .

13 Hetzel MR, Clark TJM, Braithwaite MA. Asthma analysis of sudden deaths and ventilatory arrests in hospital. BMF 1977;4:808-11.

14 Bateman JRM, Clarke SW. Sudden deaths in asthma. Thorax 1979;34:40-4. 15 Charlton IH, Charlton GFA. New perspectives in asthma care. Practitioner 1990;234:30-2.

(Accepted 2 October 1990)

\title{
Abuse of elderly people by their carers
}

\author{
Ann C Homer, C Gilleard
}

\begin{abstract}
Objective-To assess the prevalence of abuse of elderly people by their carers and the characteristics of abusers and the abused.

Design-Information on abuse and risk factors was collected over six months from carers and patients. Risk factors were identified in the abused group and compared with those in a non-abused control group.
\end{abstract}

Setting-Carers were interviewed at home; patients were examined in the wards of Putney and Barnes geriatric hospitals, London.

Subjects-All patients referred from any source for respite care to the geriatric services over a six month period and their carers.

Main outcome measures-Amount of physical and verbal abuse or neglect. Quantification of risk factors and correlation with the presence or absence of abuse.

Results $-45 \%$ Of carers openly admitted to some form of abuse. Few patients admitted abuse. The most significant risk factor for physical abuse was alcohol consumption by the carer $(\mathbf{p}<0 \cdot 001)$. Other significant risk factors were a poor pre-morbid relationship and previous abuse over many years. Abuse was often reciprocated and was associated with social dysfunction in many patients. Service delivery, respite care, and level of mental and physical disability were not significantly associated with abuse.

Conclusion-The high level of abuse found in elderly patients in respite care was particularly associated with alcohol abuse and long term relationships of poor quality, which are difficult to change. Even with increased provision of services, care in the community may not be the best solution for these people.

\section{Introduction}

Although "granny battering" was first described in Britain in $1975,{ }^{1}$ most of the research on abuse of elderly people has been carried out in North America, where statutory requirements to notify authorities of suspected cases facilitates identification for research purposes. The extent of this abuse is not known, but a social services survey in 1988 found 5\% of elderly clients were being abused, ${ }^{2}$ and this is comparable with 
studies in America, where rates of $2-4 \%$ are quoted (M Block, J Sinnot, unpublished data). ${ }^{3}$ To our knowledge there have been no previous prospective controlled studies of abuse of elderly patients in this country. We wanted to discover how much abuse there might be in a community based sample of elderly people, and whether the features already cited as indicating an increased likelihood of abuse (based on qualitative data and case reports) ${ }^{4}$ would hold true as significant risk factors for abuse. Previous research has shown that those cared for are reluctant to complain whereas the carers themselves are often willing and relieved to talk about their difficulties, ${ }^{6}$ so we interviewed the carers and asked them about abuse.

\section{Subjects and methods}

All patients already receiving regular respite care or referred for respite care to the geriatric services in Putney and Barnes over the six months from February to July 1989 were eligible for inclusion in the study. Patients attending the geriatric day hospital primarily for respite during this period were also recruited. In all, 71 patient-carer pairs were considered, and 51 carers and 43 of their patients were interviewed. A further five patients were seen without the carers. Table I shows reasons for exclusion.

Twenty four patients were diagnosed as having had a stroke, 21 were demented, and 24 patients had more than one additional problem such as Parkinson's disease, severe musculoskeletal disorders, amputations, blindness, etc. The level of dementia (mean abbreviated mental test score 6.7) made it difficult to interpret the data obtained from the patients. Because of this unreliability we decided to use only responses from carers in our analyses, although reports of abuse by patients are given for comparison (table II).

Three categories of abuse were used, following the consensus definitions described by Karl Pillemer. These were physical abuse (being pushed, grabbed, slapped, hit with a weapon, etc), verbal abuse (chronic verbal aggression, repeated insults, being sworn at, threats at least 10 times in the preceding year), and neglect (deprivation of some assistance that the elderly person needed for some important activities of daily living such as getting meals and drinks, washing, and

TABLE I - Reasons for patients and carers not being interviewed

\begin{tabular}{ll}
\hline No of patients not interviewed (by cause): & \\
Died before admission & 8 \\
Not admitted for respite care during study period & 8 \\
Moved out of area & 3 \\
Admitted to hospital for acute treatment (1 died, 1 stayed in & 2 \\
limb fitting unit) & 2 \\
\hline Inappropriate referrals (aged under 60) & 23 \\
\hline Total No of patients excluded & \\
\hline No of carers not interviewed (by cause): & 3 \\
Refused to be seen & 8 \\
Patient died before admission & 2 \\
Patient died during first respite admission & 3 \\
Moved out of area & 2 \\
Patient admitted to hospital for acute treatment & 2 \\
Inappropriate referrals & 20 \\
\hline Total No of carers excluded
\end{tabular}

TABLE II - Prevalence of abuse among 51 carers of elderly people

\begin{tabular}{lcc}
\hline & Reported by carer & Reported by patient \\
\hline Abuse by carer: & 7 & \\
$\quad$ Physical & 21 & 1 \\
$\quad$ Verbal & 6 & 9 \\
$\quad$ Neglect & & \\
Abuse by patient: & 9 & 3 \\
$\quad$ Physical & 17 & 10 \\
$\quad$ Verbal & & \\
\hline
\end{tabular}

\section{Content areas of structured interview with} carers

Relationship of carer to patient

Occupation of carer; whether they stopped work to care

Type of accommodation; who owns it; who lives in it

Amount and satisfaction with number of services received; visits by friends and neighbours; respite care

Length of time spent caring

Opportunity to socialise

Disturbed nights

Receipt of allowances

Alcohol consumption; general health; visits to general practitioner

Anger towards old people and triggers

going to the toilet). Other areas of abuse, such as financial abuse, sexual abuse, infantilisation, and abandonment, were not considered.

Carers were interviewed at home. They completed a structured interview asking about many of the risk factors that have been proposed as signals of abuse (box). In addition, carers were asked what they found most difficult about caring, why they carried on, and about abuse. Carers were also asked to complete the pre-morbid relationship rating $\mathrm{scale}^{7}$ as an index of the closeness of the relationship, the Clifton assessment procedures for the elderly behaviour rating scale ${ }^{8}$ as a measure of patient dependency, and the general health questionnaire $28^{9}$ to assess the mental health of the carers.

Patients were examined in hospital on the day of admission for respite care. Note was taken of injuries and skin markings of any type (bruise, rash, etc), diagnoses, and disabilities and time of onset. The patient's mental state was assessed with the abbreviated mental test score. $^{10}$ If the patients had sufficient cognitive function to give meaningful answers then they were asked about abuse.

Carers were grouped into those who admitted to some form of abuse and those who did not, and each group was analysed for associations with the factors mentioned above. Carers were then subdivided into those who admitted to physical abuse, verbal abuse, or neglect and compared with the rest.

\section{Results}

Twenty three ( $45 \%$ ) carers admitted to some form of abuse: $14(27 \%)$ admitted to one type, seven $(14 \%)$ to two types, and two (3\%) to all three types of abuse. Table II shows the numbers of carers reporting each type of abuse. Four carers reported mutual physical abuse and 13 carers reported mutual verbal abuse.

Characteristics of carers - There were 15 male and 41 female carers, mean age 66 (range 37-87) years. Most were spouses (27) or children (22), others being child by marriage (one), siblings (three), sibling by marriage (one), and non-kin (two). Forty nine carers lived with their dependant; seven did not. All carers who reported some form of abuse lived with their dependant. The factors most significantly associated with abuse were alcohol consumption by the carer (abusive carers mean (SD) $21 \cdot 4(19 \cdot 7)$ units/week, others $5 \cdot 2(9 \cdot 5)$ units/ week; $t=3.54, \mathrm{df}=50, \mathrm{p}<0.001)$ and abuse by the patient (correlation between degree of carer abuse and abuse from patients: Kendall's $\tau=+0.44, p<0.001$ ). The circumstances triggering physical violence in the seven carers who admitted to it were physical abuse or threats of violence by the patient in four cases, 
incontinence in one, and both in one, and one carer could not identify the trigger. Abusive carers were more likely to have stopped work to care for their relative (nine out of 23 abusive carers stopped work compared with three out of 28 non-abusive carers; $\left.\chi^{2}=4 \cdot 2, \mathrm{df}=1, \mathrm{p}<0.05\right)$. Twenty four $(48 \%)$ scored as "cases" on the general health questionnaire. Carers who admitted to physical and verbal abuse scored significantly higher on the depression subscales of the general health questionnaire than the non-abusive carers (table III). When asked what they thought was the main problem in caring for their dependant the more abusive carers more often answered that it was the behaviour of the person they cared for (Kendall's $\tau=+0.29, \quad \mathrm{p}=0.01$ ); other problems concerning physical difficulties, financial problems, social isolation, and the emotional strain of seeing changes in the dependant were not reported any more often among the abusive than the non-abusive carers. There was no difference in the level of physical dependency between abused and the non-abused patients according to the ratings on the Clifton assessment procedure for the elderly (table IV), but the abused patients were rated by their carers as more socially disturbed and presenting greater comunication problems.

The caregiving relationship - In many cases abuse had been present for a long time, often before the onset of disability. Verbal abuse was likely to have been present before the onset of disability. Seven out of 21 verbally abusive carers reported a relationship with previous verbal abuse compared with two of the 30 non-abusive group $\left(\chi^{2}=4.4, p<0.05\right)$. Two of the seven physically abusive carers and two of the 44 others reported a relationship with previous physical abuse (NS). Abusive carers rated their pre-morbid relationship as poorer than did non-abusive carers. The difference between abusers and non-abusers was significant for the ratings of those who verbally abused and those who neglected but not for the ratings of the physically abusive group. Mean (SD) rating for the 18 verbally abusive carers was $4 \cdot 3(3 \cdot 1)$ compared with $1 \cdot 5(2 \cdot 5)$ for the 28 non-abusive carers (Mann-Whitney $\mathrm{U}=96 \cdot 0$, $\mathrm{p}<0.01)$; for the six neglecting carers the mean rating was $7 \cdot 2(4 \cdot 6)$ compared with $2 \cdot 0(2 \cdot 1)$ for the 40 nonneglecting carers (Mann-Whitney $U=42, p<0 \cdot 01$ ).

Characteristics of the patient-Signs of injury or neglect in the patient were not significantly associated with reports of abuse by the carer, although paradoxically such signs were associated with abusive

TABLE III - Abuse by carer and general health questionnaire $(G H Q)$ scores

\begin{tabular}{|c|c|c|c|c|c|c|}
\hline \multirow[b]{2}{*}{$\begin{array}{l}\text { Mean scores on } \\
\text { GHQ-28 subscales }\end{array}$} & \multicolumn{2}{|c|}{ Physical abuse } & \multicolumn{2}{|c|}{ Verbal abuse } & \multicolumn{2}{|c|}{ Neglect abuse } \\
\hline & $\begin{array}{c}\text { Yes } \\
(n=7)\end{array}$ & $\begin{array}{c}\text { No } \\
(n=44)\end{array}$ & $\begin{array}{c}\text { Yes } \\
(n=21)\end{array}$ & $\begin{array}{c}\text { No } \\
(\mathbf{n}=30)\end{array}$ & $\begin{array}{c}\text { Yes } \\
(n=6)\end{array}$ & $\begin{array}{c}\text { No } \\
(n=45)\end{array}$ \\
\hline Somatic complaints & 1.9 & 1.5 & 1.9 & 1.4 & 0.8 & $1 \cdot 7$ \\
\hline Anxiety & $2 \cdot 4$ & $2 \cdot 4$ & $2 \cdot 7$ & $2 \cdot 2$ & 1.5 & $2 \cdot 5$ \\
\hline Social dysfunction & $2 \cdot 2$ & $1 \cdot 4$ & 1.8 & 1.4 & 0.3 & $1 \cdot 7^{\star}$ \\
\hline Severe depression & 1.9 & $0.8 t$ & 1.6 & $0.5 \ddagger$ & $1 \cdot 3$ & 0.9 \\
\hline
\end{tabular}

*Mann-Whitney $\mathrm{U}=58.5, \mathrm{p}=0.01$

tMann-Whitney $U=85.5, p=0.02$

$\ddagger$ Mann-Whitney $U=195, p=0.01$

TABLE IV - Abuse by carer and patient dependency ratings

\begin{tabular}{|c|c|c|c|c|c|c|}
\hline \multirow[b]{2}{*}{$\begin{array}{l}\text { Mean scores on } \\
\text { CAPE subscales }\end{array}$} & \multicolumn{2}{|c|}{ Physical abuse } & \multicolumn{2}{|c|}{ Verbal abuse } & \multicolumn{2}{|c|}{ Neglect abuse } \\
\hline & $\begin{array}{c}\text { Yes } \\
(\mathrm{n}=7\end{array}$ & $\begin{array}{c}\text { No } \\
(n=44)\end{array}$ & $\begin{array}{c}\text { Yes } \\
(\mathbf{n}=21)\end{array}$ & $\begin{array}{c}\text { No } \\
(\mathbf{n}=30)\end{array}$ & $\begin{array}{c}\text { Yes } \\
(n=6)\end{array}$ & $\begin{array}{c}\text { No } \\
(\mathrm{n}=45)\end{array}$ \\
\hline Physical disability & $8 \cdot 4$ & $7 \cdot 4$ & $7 \cdot 8$ & $7 \cdot 3$ & $8 \cdot 5$ & $7 \cdot 4$ \\
\hline Apathy & $6 \cdot 7$ & $6 \cdot 6$ & $6 \cdot 6$ & $6 \cdot 7$ & $6 \cdot 3$ & $6 \cdot 7$ \\
\hline Communication difficulties & $1 \cdot 4$ & $0 \cdot 6^{\star}$ & $0 \cdot 9$ & $0 \cdot 6$ & 1.5 & $0 \cdot 6$ \\
\hline Social disturbance & $3 \cdot 6$ & $2 \cdot 2$ & $3 \cdot 0$ & $1.9+$ & $4 \cdot 7$ & $2 \cdot 1$ \\
\hline
\end{tabular}

$\mathrm{CAPE}=$ Clifton assessment procedures for the elderly behaviour rating scale

${ }^{\star}$ Mann-Whitney $U=77 \cdot 5, p<0 \cdot 05$.

tMann-Whitney $U=214, \mathrm{p}<0.05$. behaviour by the patient (mean numbers of signs in abusive patients $0.95(1.02)$; in others $0.32(0.69)$; $t=2 \cdot 42, \mathrm{df}=46, \mathrm{p}<0 \cdot 05)$. Patients who were themselves abusive were more likely to have been diagnosed as having had a stroke ( 15 of 20 abusive patients $v$ nine of the 31 non-abusive; $\chi^{2}=9 \cdot 1, \mathrm{df}=1, \mathrm{p}<0 \cdot 01$ ).

\section{Discussion}

The idea of the typical abused victim being a frail white old woman ( 75 or over) with a well meaning daughter driven to breakdown by the stess of caring has been challenged recently. "Our findings suggest that different types of abuse arise for different reasons. Physical abuse seems to depend on the characteristics of the abuser rather than the abused. Greater alcohol consumption among those committing physical abuse has been found by other researchers and supports the idea that physical abuse is perpetrated by people with disturbed and disorganised personalities irrespective of the physical and mental state of the abused. ${ }^{12}$ The only significant feature of patients who were physically abused was their poor communication (as rated by the carers). Communication is a two way process, however, and no such difference was seen in the ratings of hospital staff for the same patients. Verbal abuse and neglect were both significantly related to poor premorbid relationships, an association not seen for physical abuse. Verbal abuse was commoner, was more often a feature of the relationship before any dependency or illness intervened, and was associated with depresssion and anxiety in the carers. Neglect was associated with socially dysfunctional carers.

Many carer-patient couples had a longstanding mutually abusive relationship. Among married couples they may be seen as the elderly graduates of domestic violence further stressed by the disabilities associated with aging. It is still not known whether children who abuse their elderly parents have themselves been brought up in an atmosphere of abusive behaviour, ${ }^{12}$ although there were examples in our study: one son remarked that his father had always been a sadistic so and so, and now he was paying him back. Whether it is the spouse or, even less socially acceptable, the child who is the abuser it seems from our study that much of the reason for the abusiveness lies in the relationship rather than in the external circumstances or the illness or dependency characteristics of the abused person.

Few of the abused patients actually complained of being abused themselves (one of the seven who were physically abused and nine of the 21 who were verbally abused patients did so). Where abuse is suspected, even when the patient denies it, the carer should always be questioned. Carers are willing to talk about their difficulties under the right circumstances (in privacy, to a non-judgmental listener, and on home territory if possible) and often express relief at sharing their problems with someone else. This has been noted by others who have interviewed carers directly.

Our study has some important negative findings. Firstly, physical signs and reports of abuse were not correlated. It is said that bruising can be assessed to determine whether or not it is due to a fall. ${ }^{13}$ In our experience the pattern of injuries in these patientsmany of whom had had strokes and had few of the normal protective reflexes on falling-was unclassifiable. Secondly, social isolation and lack of services, which have been associated with abuse, ${ }^{12}$ showed no association with any measure of abuse in our study, raising doubts about the potential for prevention of abuse by increased service delivery. Finally, the lack of association between abuse and the diagnosis of dementia or degree of mental impairment of the patient is noteworthy. The presence or absence of disruptive behaviour may be more important than cognitive 
impairment, and the quality of the past relationship more important still.

In the light of these findings, what would be the best way to help and protect these people? It has been proposed that cases of material and physical abuse may be more successfully resolved if abuse is treated as a criminal act rather than a social problem. ${ }^{3}$ Abuse is, after all, a crime rather than a diagnosis. It is not easy to treat it as such, as shown by the experience in America, where reporting of suspected cases is mandatory in many states. ${ }^{14}$ If patients are reluctant to admit to abuse they are unlikely to press charges, and there is also the difficult question of the competence of mentally impaired patients when making allegations.

As there is no legal requirement in Britain to notify cases of abuse the usual response is to offer respite care on an inpatient or daycare basis, increase the input from formal services, and monitor the situation. If this fails, then the old person is often removed from his or her home (even when it is thought that the carer should be the one to leave). Our study would question the value of increased input of formal services to relieve abusive circumstances. Few carers expressed the desire for increased home help or district nursing input, and it was not the physical or personal aspects of caring that caused the distress; distress was caused by the socially disruptive and abusive behaviour. When this behaviour has been present for many years as an integral part of a relationship it will be very resistant to change. Efforts to change the behaviour of the patient or improve the coping skills of the carer can be made with the help of a clinical psychologist or psychogeriatrician. Carers may find carer support groups helpful, along with counselling ${ }^{1516}$ and advice on alcohol abuse. Family therapy may be of benefit. Failing this, a separation between patient and carer should be considered. Care in the community may not offer the best deal for everyone.

I thank Dr Andy Neil for his encouragement and help with setting up this study and Tamsin Wade for her great help in data collection. This study was supported by a start up grant from the British Geriatrics Society.

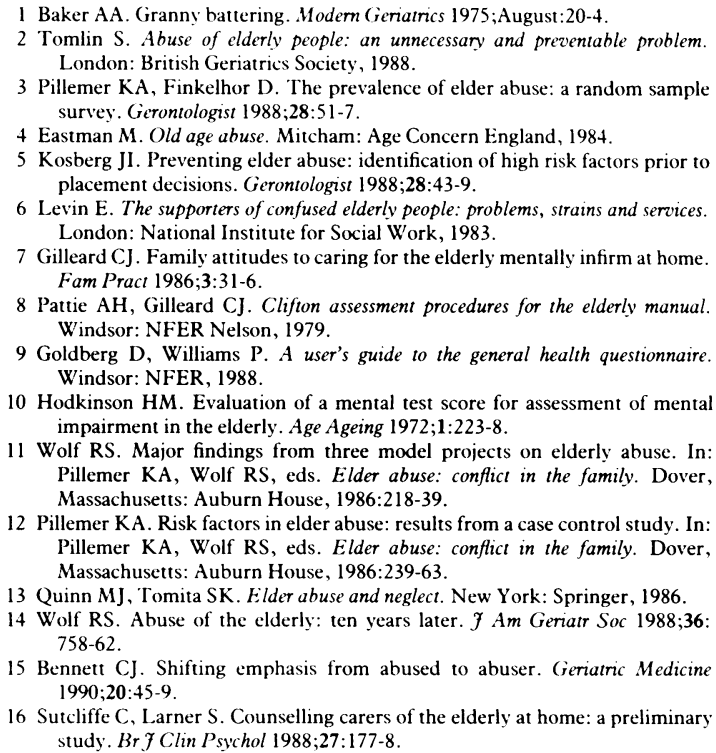
placement decisions. Gerontologist 1988;28:43-9.

6 Levin E. The supporters of confused elderly people: problems, strains and services. London: National Institute for Social Work, 1983.

7 Gilleard CJ. Family attitudes to caring for the elderly mentally infirm at home. Fam Pract 1986;3:31-6.

8 Pattie AH, Gilleard CJ. Clifton assessment procedures for the elderly manual. Windsor: NFER Nelson, 1979

9 Goldberg D, Williams P. A user's guide to the general health questionnaire. Windsor: NFER, 1988.

10 Hodkinson HM. Evaluation of a mental test score for assessment of mental impairment in the elderly. Age Ageing 1972;1:223-8.

11 Wolf RS. Major findings from three model projects on elderly abuse. In: Pillemer KA, Wolf RS, eds. Elder abuse: conflict in the family. Dover, Massachusetts: Auburn House, 1986:218-39.

12 Pillemer KA. Risk factors in elder abuse: results from a case control study. In : Pillemer KA, Wolf RS, eds. Elder abuse: confict in the family. Dover Massachusetts: Auburn House, 1986:239-63.

13 Quinn MJ, Tomita SK. Elder abuse and neglect. New York: Springer, 1986.

14 Wolf RS. Abuse of the elderly: ten years later. $\mathcal{F}$ Am Geriatr Soc 1988;36: 758-62.

15 Bennett CJ. Shifting emphasis from abused to abuser. Geriatric Medicine 1990;20:45-9.

16 Sutcliffe C, Larner S. Counselling carers of the elderly at home: a preliminary study. Br 7 Clin Psychol 1988;27:177-8.

Accepted 18 September 1990

\title{
Progression of HIV infection in misusers of injected drugs who stop injecting or follow a programme of maintenance treatment with methadone
}

\author{
Rainer Weber, Bruno Ledergerber, Milos Opravil, Walter Siegenthaler, Ruedi Lüthy
}

Division of Infectious

Diseases, Department of Medicine, University Hospital, CH-8091 Zürich, Switzerland

Rainer Weber, MD, senior registrar in internal medicine Bruno Ledergerber, PHD, consultant in biostatistics

Milos Opravil, MD, senior registrar in internal medicine Walter Siegenthaler, MD, professor of medicine, head of medical policlinic

Ruedi Lüthy, MD, professor of medicine, head of division of infectious diseases

Correspondence and requests for reprints to: Professor Lüthy.

\section{Abstract}

Objective-To see whether misusers of injected drugs who stop injecting or switch to a programme of maintenance treatment with methadone have a reduced risk of progression of HIV infection when compared with a group of persistent misusers.

Design-Observational cohort study in HIV seropositive subjects with a current or past history of misusing injected drugs.

Setting-HIV outpatient clinic at the University Hospital of Zurich, Switzerland.

Patients -297 Current and former parenteral drug misusers (median age 27) with asymptomatic HIV infection. During the observation period 80 subjects adhered to a programme of maintenance treatment with methadone, 124 continued with parenteral drug misuse, and 93 former misusers remained free of illicit drugs. No antiretroviral treatment was given during the study.

Main outcome measures-Probability of progression of HIV infection from asymptomatic to symptomatic (Centers for Disease Control stage IV) as calculated by life table analysis and compared in the three groups of patients by means of a log rank test, and predictors of disease progression as analysed with a Cox proportional hazards regression model.

Results - The 297 patients were followed up for a median of 16 months. The median duration of injecting drug misuse before enrolment was $7 \cdot 1$ years. There were no significant differences among the three groups with respect to $\mathrm{CD4}+$ counts at the beginning of the study (median $0.44 \times 10^{\%} / 1$ ). Life table analysis showed a significantly lower probability of progression of HIV disease in both the methadone treated group and former drug misusers than in persistent injecting drug misusers. Multivariate regression analysis showed a relative risk of progression of the disease of $1.78(95 \%$ confidence interval 1.20 to $2.67 ; \mathrm{p}<0.01$ ) in persistent injecting drug misusers, $0.48(0.29$ to $0.77 ; \mathrm{p}<0.01)$ in the methadone treated group, and $0.66(0.41$ to 1.06 ; $\mathbf{p}=\mathbf{0 . 0 8 5}$ ) in former drug misusers.

Conclusions-Stopping the misuse of injected drugs slows the progression of HIV disease in infected subjects. Drug treatment programmes are effective in secondary prevention of HIV associated morbidity.

\section{Introduction}

To establish strategies in the prevention and treatment of HIV infection in injecting drug misusers we need data on the natural course of HIV infection in these subjects. Despite the high incidence of AIDS among injecting drug misusers in the United States and Europe these data are rare, primarily because of 